\title{
LA TEORÍA DE LA ACCIÓN COMUNICATIVA DE JÜRGEN HABERMAS. UNA INTERPRETACIÓN Y SUS POSIBLES APLICACIONES EN LAS CIENCIAS DE LA GESTIÓN*
}

\author{
JÜRGEN HABERMAS' THEORY OF COMMUNICATIVE ACTION. \\ AN INTERPRETATION AND ITS POSSIBLE APPLICATIONS IN \\ MANAGEMENT SCIENCES
}

A TEORIA DA ACČÃO COMUNICATIVA DE JÜRGEN HABERMAS. UMA INTERPRETAÇÃO E AS SUAS POSSIIVEIS APLICAÇÕES NAS CIÊNCIAS DA GESTÃO

LA THEORIE DE L'ACTION COMMUNICATIVE DE JÜRGEN HABERMAS. UNE INTERPRETATION ET SES APPLICATIONS POSSIBLES EN SCIENCES DE LA GESTION

SIMÓN ANDRÉS IDROBO ZÚÑIGA, Ph.D $D^{\dagger}$

Fecha de recepción: 18 de septiembre de 2020

Fecha de aprobación: 20 noviembre de 2020

RESUMEN

Una observación sobre las organizaciones como células sociales permite identificar que estas actúan en un marco de racionalidad

* Este artículo es de tipo reflexión.

† Profesor asociado, Universidad del Cauca, Ph.D en Administración, Universidad Andina Simón Bolívar, Quito, Ecuador; magíster en Administración con especialidad en Finanzas, Instituto Tecnológico de Monterrey, México; contador público, Universidad del Cauca; especialista en Finanzas, Universidad EAFIT, Medellín; especialista en Administración Financiera, Universidad EAN, Bogotá; especialista en Gerencia de Proyectos, Universidad del Cauca; especialista en Revisoría Fiscal y Auditoría Externa, Universidad Autónoma de Bucaramanga; especialista en Gerencia Tributaria, Universidad Libre; integrante del grupo de investigación "Contabilidad sociedad y desarrollo"; miembro académico del Centro Colombiano de Investigaciones Contables C-Cinco. - https: / / orcid.org/0000-000 1-9798-172X.

Criterio Libre N. ${ }^{\circ} 33$ Bogotá (Colombia) Julio-Diciembre 2020

pp. 35-64

ISSN 1900-0642

ISSN electrónico 2323-0886 


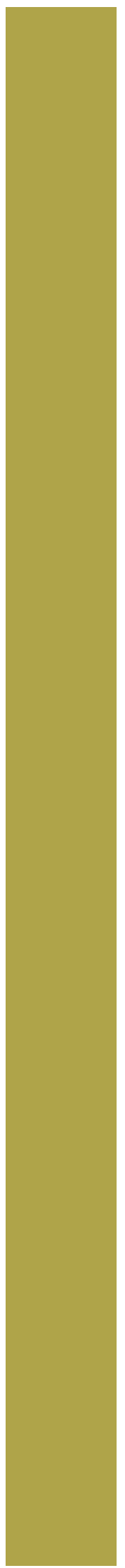

instrumental, descrita e instrumentada a partir de las afirmaciones de la naciente sociología y, en especial, por el pensamiento de Max Weber, pionero de la escuela burocrática que centró sus afirmaciones en un enfoque teleológico y a la vez procedimental a partir de la interacción de la dualidad "deber ser" y "qué hacer". Este pensamiento se hizo dominante en las llamadas ciencias de la gestión, generando acciones caracterizadas por la dominación sobre lo humano, su libertad y autonomía.

El esfuerzo intelectual de este trabajo es encontrar o coadyuvar a un enfoque diferente en las ciencias de la gestión, partiendo del reconocimiento del contexto histórico del surgimiento del pensamiento crítico, en la concepción de la Escuela de Frankfurt, en un escenario de crisis espiritual y de la cultura que abordó las tareas de una redefinición de la cultura, la revisión de legados ideales, hegemónicos y centrales del pensamiento de la modernidad clásica, la modernidad ilustrada, la modernidad burguesa y sus crisis de conceptos como razón, subjetividad, tiempo, narración, realidad, progreso, verdad y valor. Gran importancia se otorga a la producción de Jurgen Habermas, identificando en su trabajo las categorías de "mundo de la vida", "racionalidad" y "comunicación" y su crítica sobre los mecanismos integradores como el dinero a través del mercado, poder en la estructura de las organizaciones y la solidaridad generada en virtud de normas, valores y comunicación.

Sobre estas bases se justifica la necesidad de la teoría de la acción comunicativa para entender y superar la "racionalidad instrumental" para que sea la gestión social (o de inclusión) la que colonice a la gestión estratégica (o de exclusión) y no como ha venido sucediendo socio-históricamente. Bajo las anteriores perspectivas se pretende contribuir al debate de cómo lograr una gestión "económicamente eficaz" y "humanamente viable" para hallar una reificación de la potenciación de los sujetos, nunca su aniquilación, pues las organizaciones son redes de la trama humana que trasciende los procesos instrumentales.

PALABRAS CLAVE:

gestión dialógica; racionalidad comunicativa; racionalidad instrumental; reificación; teoría de la acción comunicativa; teoría crítica.

CLASIFICACIÓN JEL:

L21, L22. 


\section{ABSTRACT}

An observation of organizations as social cells allows us to identify that they act within a framework of instrumental rationality, described and instrumented from the statements of the nascent sociology and, especially, by the thinking of Max Weber, pioneer of the bureaucratic school, who focused his statements on a teleological and at the same time procedural approach based on the interaction of the duality "should be" and "what to do". This thinking became dominant in the so-called management sciences, generating actions characterized by domination over the human, its freedom and autonomy.

The intellectual effort of this work is to find or contribute to a different approach in the management sciences, starting from the recognition of the historical context of the emergence of critical thinking, in the conception of the Frankfurt School, in a scenario of spiritual and cultural crisis that addressed the tasks of a redefinition of culture, the revision of ideal, hegemonic and central legacies of the thought of classical modernity, enlightened modernity, bourgeois modernity and its crisis of concepts such as reason, subjectivity, time, narrative, reality, progress, truth and value. Great importance is given to the production of Jürgen Habermas, identifying in his work the categories of "lifeworld", "rationality" and "communication" and his critique of integrating mechanisms such as money through the market, power in the structure of organizations and solidarity generated by virtue of norms, values and communication.

On these bases, the need for the theory of communicative action is justified in order to understand and overcome "instrumental rationality" so that social management (or inclusion) colonizes strategic management (or exclusion) and not as it has been happening socio-historically. Under the above perspectives, the aim of the article is to contribute to the debate on how to achieve an "economically efficient" and "humanly viable" management in order to find a reification of the empowerment of subjects, never their annihilation, since organizations are networks of the human fabric that transcends instrumental processes.

Keywords: communicative rationality; critical theory; dialogic management; instrumental rationality; reification; theory of communicative action.

JEL classification: L21, L22.

RESUMO

Uma observação sobre as organizações como células sociais permitenos identificar que actuam num quadro de racionalidade instrumental, descrito e instrumentado a partir das declarações da sociologia 


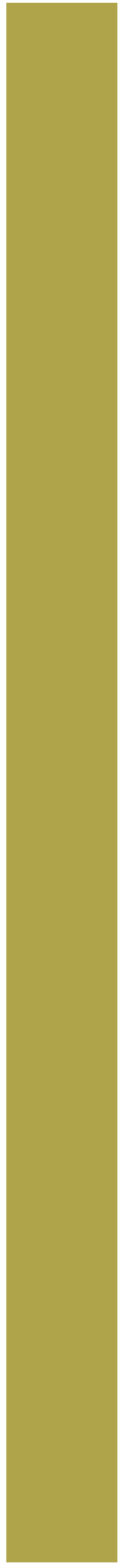

nascente e, especialmente, pelo pensamento de Max Weber, pioneiro da escola burocrática que centrou as suas declarações numa abordagem teleológica e ao mesmo tempo processual a partir da interacção da dualidade "deve ser" e "o que fazer". Este pensamento tornou-se dominante nas chamadas ciências de gestão, gerando acções caracterizadas pela dominação sobre o humano, a sua liberdade e autonomia.

O esforço intelectual deste trabalho consiste em encontrar ou contribuir para uma abordagem diferente nas ciências de gestão, partindo do reconhecimento do contexto histórico da emergência do pensamento crítico, na concepção da Escola de Frankfurt, num cenário de crise espiritual e cultural que abordou as tarefas de uma redefinição da cultura, a revisão dos legados ideais, hegemónicos e centrais do pensamento da modernidade clássica, da modernidade iluminada, da modernidade burguesa e da sua crise de conceitos como razão, subjectividade, tempo, narrativa, realidade, progresso, verdade e valor. É dada grande importância à produção de Jürgen Habermas, identificando no seu trabalho as categorias de "mundo da vida", "racionalidade" e "comunicação" e a sua crítica de integração de mecanismos como o dinheiro através do mercado, poder na estrutura das organizações e solidariedade gerada em virtude de normas, valores e comunicação.

Sobre estas bases, justifica-se a necessidade da teoria da acção comunicativa para compreender e superar a "racionalidade instrumental" de modo a que a gestão social (ou inclusão) colonize a gestão estratégica (ou exclusão) e não como tem vindo a acontecer sóciohistóricamente. Sob as perspectivas anteriores pretende-se contribuir para o debate sobre como conseguir uma gestão "economicamente eficiente" e "humanamente viável" para encontrar uma reificação da potenciação dos sujeitos, nunca a sua aniquilação, porque as organizações são redes do tecido humano que transcendem os processos instrumentais.

Palavras-chave: gestão dialógica; racionalidade comunicativa; racionalidade instrumental; reificação; teoria da acção comunicativa; teoria crítica.

Classificação JEL: L2 1, L22.

\section{RESUME}

Une observation des organisations en tant que cellules sociales nous permet d'identifier qu'elles agissent dans un cadre de rationalité instrumentale, décrit et instrumenté à partir des énoncés de la 
sociologie naissante et, en particulier, par la pensée de Max Weber, pionnier de l'école bureaucratique qui a axé ses énoncés sur une approche téléologique et en même temps procédurale à partir de l'interaction de la dualité "devrait être» et «que faire». Cette pensée est devenue dominante dans ce qu'on appelle les sciences de la gestion, générant des actions caractérisées par la domination sur l'humain, sa liberté et son autonomie.

L'effort intellectuel de ce travail est de trouver ou de contribuer à une approche différente dans les sciences de la gestion, à partir de la reconnaissance du contexte historique de l'émergence de la pensée critique, dans la conception de l'École de Francfort, dans un scénario de crise spirituelle et culturelle qui a abordé les tâches d'une redéfinition de la culture, la révision des héritages idéaux, hégémoniques et centraux de la pensée de la modernité classique, la modernité éclairée, la modernité bourgeoise et sa crise de concepts tels que la raison, la subjectivité, le temps, le récit, la réalité, le progrès, la vérité et la valeur. Une grande importance est accordée à la production de Jürgen Habermas, identifiant dans son œuvre les catégories de «monde de vie», de "rationalité» et de "communication» et sa critique des mécanismes d'intégration tels que l'argent par le marché, le pouvoir dans la structure des organisations et la solidarité générée en vertu des normes, des valeurs et de la communication.

Sur ces bases, la nécessité de la théorie de l'action communicative se justifie pour comprendre et dépasser la «rationalité instrumentale» afin que la gestion sociale (ou l'inclusion) colonise la gestion stratégique (ou l'exclusion) et non pas comme cela s'est passé socio-historiquement. Dans le cadre des perspectives précédentes, l'objectif de l'article est de contribuer au débat sur la manière de parvenir à une gestion «économiquement efficace» et «humainement viable» afin de trouver une réification de l'autonomisation des sujets, jamais leur anéantissement, car les organisations sont des réseaux du tissu humain qui transcendent les processus instrumentaux.

Mots clés: gestion dialogique; rationalité communicative; rationalité instrumentale; réification; théorie de l'action communicative; théorie critique.

Classification JEL: L21, L22. 


\section{INTRODUCCIÓN}

Figura 1. Angelus Novus de Paul Klee.

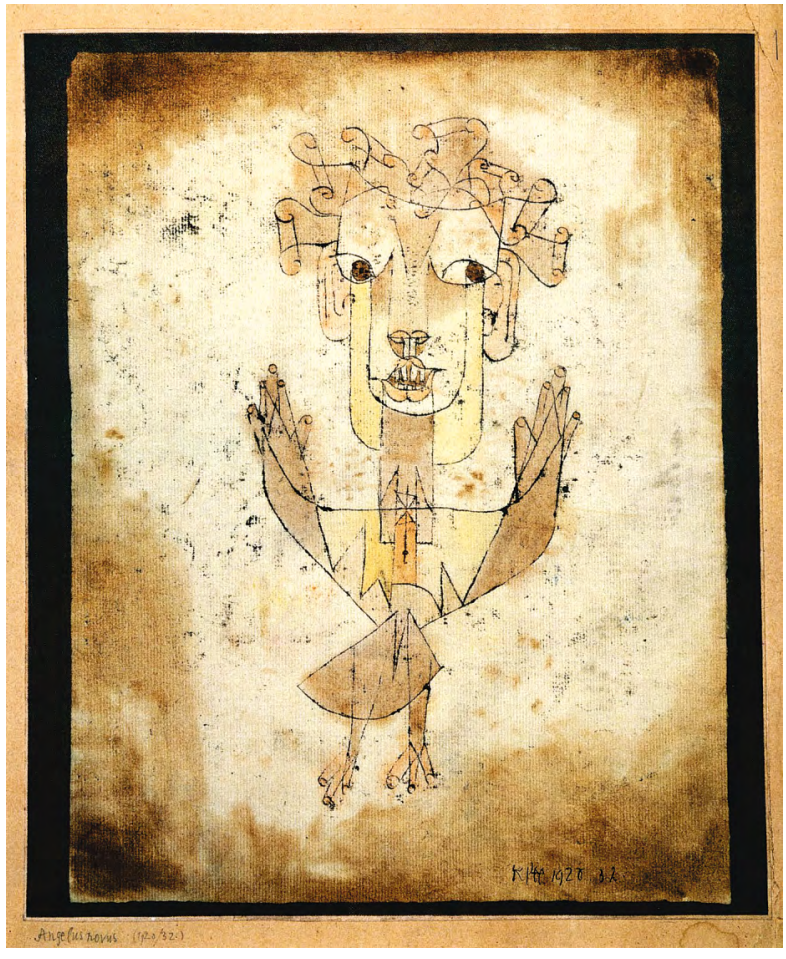

Fuente: https://es.wikipedia.org/wiki/Angelus Novus

En el texto Tesis de la filosofía de la historia, en las cuales recoge el espíritu de su tiempo histórico y cultural, Walter Benjamín escribió una de las páginas más profundas y hermosas en todo sentido. La tesis IX nos introduce metafóricamente en el modo de ver el progreso. Se trata de un pasaje que inicia con una evocación de una obra de Paul Klee titulada Angelus Novus que espero sea el legado intelectual y las guías estéticas y espirituales de este ensayo. Dice allí:

Hay un cuadro de Klee que se titula Angelus Novus [el Nuevo Ángel, el ángel de la cultura nueva, o moderna, de nuestra época]. Se ve en él un ángel [a un ser absolutamente inocente, sin culpa] al parecer en el momento de alejarse de algo sobre lo cual clava la mirada. Tiene los ojos desorbitados, la boca abierta y las alas tendidas [hasta aquí la descripción del Angelus Novus de Klee; a partir de este punto sigue la evocación de Benjamin de otro ángel: el ángel de la historia]. El ángel de la historia debe tener ese aspecto [mira algo horrorizado, con las alas extendidas]. Su rostro está vuelto hacia el pasado. En lo que para nosotros aparece como una cadena de acontecimientos, él ve una catástrofe única, que arroja a sus pies ruina sobre ruina, amontonándolas sin cesar [Benjamin describe lo que ve este ángel de la historia inventado, una catástrofe única en marcha, sin cesar ruina sobre ruina, como instantánea, antes de describir lo que ello suscita en el ser inocente]. El ángel quisiera detenerse, despertar a los muertos y recomponer lo destruido [es decir, reparar, redimir el pasado, quitarle infelicidad]. Pero un huracán sopla desde el paraíso y se arremolina en sus alas, y es tan fuerte que el ángel ya no puede plegarlas. Este huracán lo arrastra irresistiblemente hacia el futuro, al cual vuelve las espaldas, mientras el cúmulo de ruinas crece ante él hasta el cielo. Este huracán es lo que nosotros llamamos progreso. (Benjamin, 1967, p. 46).

El "progreso" es la fuerza cultural mítica que impide obrar al inocente; si algo caracteriza la época de progreso son sus logros intrínsecamente técnico-científicos o de racionalidad instrumental, la cual se halla en manos opresoras. Benjamin percibe la peligrosidad de la racionalidad instrumental, agenciada hoy por procesos de deslocación (mundialización) de capitales y empresas materializada con graves problemas demográficos, energéticos, de recursos y residuos, con ambiente deteriorado, con multitud de especies exterminadas por el industrialismo; por su parte propone una actividad productiva coherente con las características de la base de nuestra existencia, no explotadoras ni destructivas.

El presente ejercicio intelectual no pretende ser de ninguna manera una propuesta acabada, y por el contrario, es más un acercamiento sistemático de carácter académico e intuitivo, el cual está inspirado en el trabajo y la obra de largo aliento que viene adelantando sobre los frankfurtianos y en especial de Jürgen Habermas, el profesor Fernando G. Tenorio a quien deseo 
expresar mi agradecimiento. Las ideas que intento concretar son el producto de los sucesivos encuentros académicos con el profesor Tenorio en desarrollo de la cátedra "Pensamiento crítico y pensamiento administrativo" llevadas a cabo en el doctorado de Administración de la Universidad Andina Simón Bolívar, entendiendo por "crítico" el cuestionamiento no solo de determinadas prácticas y conductas individuales, sino del orden social capitalista; de igual modo esta reflexión teorética se inscribe en la corriente intelectual "Critical Management Studies" o "estudios críticos de la gestión", línea de investigación que está inspirada en la "teoría crítica" y el "postestructuralismo" en los cuales se denuncian los mecanismos de dominación ideológica capitalista a nivel organizacional estimulando la resistencia de la colonialidad del poder y del saber hegemónico organizacional.

El pensamiento crítico fue planteado por las diversas generaciones de intelectuales que conformaron lo que se denominó el Instituto de Investigación Social: Max Horkheimer, Theodor W. Adorno, Walter Benjamin, Herbert Marcuse, Jürgen Habermas, entre otros, que posteriormente se denominó Escuela de Frankfurt; las características generacionales, biográficas e intelectuales de estos pensadores de comienzos del siglo XX muestran que todos son hijos de una enorme crisis espiritual, de una profunda redefinición de la cultura, de un tiempo histórico que comenzó a revisar profunda y críticamente los legados ideales, hegemónicos y centrales del pensamiento de la modernidad clásica, la modernidad ilustrada, la modernidad burguesa lla crisis del concepto de razón, la crisis del concepto de subjetividad, del concepto de tiempo, del concepto de narración, del concepto de realidad, del concepto de progreso, la crisis del concepto de verdad, del concepto de valor). Todos, de algún modo, son exponentes de un movimiento de revisión crítica, de un intento de reescribir la gramática profunda de la sociedad moderna. En este orden de ideas la Escuela de Frankfurt se constituye en una corriente y alternativa

\section{El "progreso" es la fuerza cultural}

mítica que impide obrar al

inocente; si algo caracteriza la

época de progreso son sus logros

intrínsecamente técnico-científicos

o de racionalidad instrumental, la

cual se halla en manos opresoras 
El modelo de Jürgen Habermas explicitado en su teoría de la acción comunicativa es de carácter filosófico, sociológico y político, en la cual si bien guarda estrecha relación con una teoría eminentemente lingüistica y comunicativa, no impide que pueda presentarse como un posible modelo interpretativo de la realidad social y organizacional en donde las prácticas sociales del mundo de la vida pública y privada no sean de exclusión sino, por el contrario, de inclusión de los sujetos que la componen, por cuanto están dotados de capacidad de habla e interacción ... epistémico crítica para las ciencias sociales permitiéndoles a los cientistas sociales hacer inteligible las problemáticas de la sociedad moderna y a las ciencias de la gestión desde un enfoque interdisciplinario es interpretar la realidad de la sociedad burguesa para ayudar a la emancipación del hombre y la sociedad.

Una de las referencias más explícitas de la teoría crítica para interpretar la modernidad como proyecto inconcluso la plantea el filósofo alemán Jürgen Habermas (frankfurtiano de la segunda generación). Habermas tiene un pensamiento más optimista y propone la implementación de un modelo alternativo: la "racionalidad comunicativa". Este modelo busca conciliar la antinomia entre "racionalidad instrumental" versus la "racionalidad sustantiva", y representa una salida al "pesimismo crítico" referenciado en su sentido y alcance en el libro Dialéctica de la llustración de Max Horkheimer, Theodor W. Adorno (frankfurtianos de la primera generación). Ese pesimismo crítico lo referencia Adorno cuando escribe:

... la razón es capaz de producir
dispositivos profundamente irracionales
(...) La razón pura se convirtió en
anti-razón, en conducta impecable y
vacua (...) El progreso se invierte y se
convierte en regreso (...) La tendencia
de la autodestrucción pertenece desde
el comienzo a la racionalidad, no solo
idealmente sino también prácticamente
(...) Su "irracionalismo" se deduce de la
esencia misma de la razón dominante y
del mundo hecho a su imagen.

La razón a la que se refiere es la técnicocientífica, o a lo que después los pensadores de Frankfurt denominaron "razón instrumental", una razón, como escriben Adorno y Horkheimer, que se ha convertido en una "finalidad sin fin", que, precisamente por ello, se puede utilizar para cualquier fin, la cual es capaz de producir dispositivos para la aniquilación cuantitativa de los seres humanos. 
El modelo de Jürgen Habermas explicitado en su teoría de la acción comunicativa es de carácter filosófico, sociológico y político, en la cual si bien guarda estrecha relación con una teoría eminentemente lingüística y comunicativa, no impide que pueda presentarse como un posible modelo interpretativo de la realidad social y organizacional en donde las prácticas sociales del mundo de la vida pública y privada no sean de exclusión sino, por el contrario, de inclusión de los sujetos que la componen, por cuanto están dotados de capacidad de habla e interacción; esta teoría permite analizar la sociedad como dos formas de racionalidad que están en juego simultáneamente: la racionalidad sustantiva del mundo de la vida y la racionalidad formal del sistema, pero donde el mundo de la vida representa una perspectiva interna como el punto de vista de los sujetos que actúan sobre la sociedad, mientras que el sistema representa la perspectiva externa, como la estructura sistémica (la racionalidad instrumental, tecno-burocrática, de las instituciones). En este orden de ideas Habermas sostiene, además, en términos generales, que las sociedades contemporáneas se hallan integradas a través de tres medios o mecanismos. El "dinero" como medio se institucionaliza a través del "mercado"; el "poder" como medio se institucionaliza en las "organizaciones", y la "solidaridad" se genera en virtud de normas, valores y comunicación.

El propósito de este ensayo es mostrar que necesitamos la teoría de la acción "racionalidad comunicativa" para entender y superar la "racionalidad instrumental", la cual históricamente ha venido determinando el deber ser y el qué hacer de las organizaciones públicas y privadas. De tal manera que sea la gestión social (o de inclusión) la que colonice a la gestión estratégica (o de exclusión) y no al revés, como ha venido sucediendo sociohistóricamente. Para ello la teoría de acción comunicativa establece tres categorías de análisis indispensables y que tienen profundas implicaciones para las ciencias de la gestión tanto para sus desarrollos teóricos como para sus desarrollos práctico. Estas categorías epistémicas son: el mundo de la vida; la racionalidad; la comunicación. Bajo las anteriores perspectivas, este ensayo pretende también contribuir al debate de cómo lograr una gestión "económicamente eficaz" y "humanamente viable" de manera que haya una reificación (concepto clave de la filosofía crítica) de la potenciación de los sujetos, nunca su aniquilación, pues las organizaciones son redes de la trama humana que trasciende los procesos instrumentales. Para materializar este ejercicio intelectual se ha planteado el siguiente itinerario metodológico así: en primer lugar, se pretende situar en su contexto histórico el surgimiento de la llamada Escuela de Frankfurt, y la teoría de la acción comunicativa dibujando sus líneas maestras sus preocupaciones teóricas fundamentales y su vigencia actual. En segundo lugar, se pretende hacer una caracterización teórica del modelo pragmático de Jürgen Habermas como desafío de carácter intelectual para las ciencias de la gestión a la hora de su puesta en práctica frente al conflicto histórico y dialéctico entre los imperativos categóricos de la racionalidad instrumental y racionalidad sustantiva. En un tercer lugar se describen las categorías de análisis desde la perspectiva de la "racionalidad comunicativa" indispensables para repensar teóricamente el deber ser y el qué hacer en las "ciencias de la gestión". En un cuarto lugar se plantea cómo la "racionalidad comunicativa" materializada en "gestión dialógica" o "gestión social" podría constituirse en una bifurcación para superar la categoría de análisis de "racionalidad instrumental" sobre la cual teóricamente sustentan las organizaciones su razón de ser. Por último, se plantean unas reflexiones finales. 


\section{- CRÍTICA FILOSÓFICA DE LA RAZONN ILUSTRADA EN EL MARCO TEORETICO DE LA OBRA CONJUNTA DE THEODOR W. ADORNO - MAX HORKHEIMER Y JURGEN HABERMAS}

El estado del arte de la discusión actual de la "razón ilustrada" y sus consecuencias teóricoprácticas no resulta fácil de establecer, existe un campo muy amplio de diseminación y relativismo epistemológico al respecto (Suares Molano, 2006. p. 11. El objeto de la crítica de la "razón ilustrada" lo describe Hegel, quien anuncia que "el único pensamiento que aporta [la filosofía] es el simple pensamiento de la razón, de que la razón rige el mundo y de que, por tanto, también la historia universal ha transcurrido racionalmente" (Hegel, 1974, p. 43). Con ello Hegel resalta cómo la cultura occidental encarnada en Europa (eurocentrismo) convierte la razón en una categoría trascendental capaz de determinar los fines y los medios con que se justifica y legitima el conocimiento y las acciones humanas, convirtiendo la razón en un dios, el cual promete "libertad" y "progreso" indefinidos, estableciéndose la revolución cultural denominada "modernidad", la cual es el resultado de un largo y lento proceso sociohistórico y una de sus consecuencias es el inmenso valor asignado a la razón como instrumento y dominio de la intelección de la vida material y espiritual de los hombres. La modernidad dio origen a la idea y a la representación de un hombre-persona- sujeto actuante, dominante, que creía poder tener el control total de su hacer y de sus deseos, el poder de la razón asociado a la autonomía subjetiva del espíritu humano potenció el deseo humano de organizar y controlar el medio natural para manipular a los demás y a su entorno. Por su parte, Kant en respuesta a ¿qué es la llustración? Responde:
La llustración consiste en el hecho por el cual el hombre sale de la minoría de edad. Él mismo es culpable de ella. La minoría de edad estriba en la incapacidad de servirse del propio entendimiento, sin la dirección de otro. Uno mismo es culpable de esta minoría de edad, cuando la causa de ella no yace en un defecto del entendimiento, sino en la falta de decisión y ánimo para servirse con independencia de él, sin la conducción de otro. ¡Sapere aude!, ten el valor de servirte de tu propio entendimiento (Kant, 1964, p. 58).

De ello se deriva la idea de que la minoría de edad se abandona mediante el ejercicio pleno de la razón, el juicio y el entendimiento. Por su parte, los filósofos contemporáneos consideran que el auténtico padre de la puesta en duda de la absolutez de la razón es Nietzsche, en sus textos (Mas allá del bien y el mal, Sobre la verdad y la mentira en el sentido extra moral, Así habló Zaratustra) aparecen duras críticas a la idea de la razón occidental entendida como ese instrumento privilegiado para acceder al conocimiento tanto de la naturaleza como del espíritu humano, lo que denuncia Nietzsche es el efecto eminentemente político que significó privilegiar la razón y no los sentimientos o los valores como otras formas para interpretar el mundo, la crítica de Nietzsche desemboca en un rechazo a la razón como instancia legitimadora de la verdad del hombre, todo pensamiento es solo una interpretación y por ello ningún concepto puede reclamar para sí un valor absoluto. En consecuencia, al igual que Nietzsche en otros terrenos, Horkheimer y Adorno concluyen que el camino de la civilización occidental conduce en última instancia a la negación de todos los valores, al "nihilismo" (Horkheimer, 1947, p. 40).

Hoy asistimos a una crítica polisémica de la modernidad o modelos de hacer filosofía denominados: reconstrucción de la racionalidad (critica alemana: Max Horkheimer - Theodor Adorno - Jürgen Habermas), deconstrucción de la racionalidad (crítica francesa: Jean Francois Lyotar - Michel Foucault - Jaques Derrida - Gillez 
Deleuze) y negación de la racionalidad (crítica norteamericana: Ludwing Wittgenstein - Richard Rorty) (Suares Molano, 2006. pp. 42, 71, 105). Por ser de nuestro interés para los efectos de este ensayo, solo abordaremos en términos muy resumidos la postura crítica de la reconstrucción de la racionalidad apartado conceptual y epistemológico en el cual se enmarcan los logros teóricos de Habermas.

La llamada Escuela de Frankfurt surge con la fundación, en 1923, del Instituto para la investigación Social, en el que los estudios interdisciplinares inspirados en el marxismo contribuyeran a lograr una visión adecuada de la sociedad, esta propuesta intentaba coordinar tanto las metodologías como los resultados de las teorías dominantes en el mundo académico, la lingüística, el marxismo y el psicoanálisis. Señalando las incertidumbres en el saber de las ciencias sociales, junto a la interdisciplinariedad que acabamos de comentar, hay que destacar también dos características fundamentales: la reflexividad del pensamiento y su dimensión crítica. El pensamiento debe nacer, a ojos de Horkheimer, a partir de las contradicciones de la realidad, desde todo aquello que nos hace pensar una sociedad distinta. En virtud de lo anterior, ante la pregunta ¿̇cómo conciliar la razón con la vida de los hombres? la denominada Escuela de Frankfurt pretende hacer una reconstrucción de la racionalidad (crítica alemana: Max Horkheimer - Theodor Adorno - Jürgen Habermas). La obra conjunta de los filósofos frankfurtianos Theodor W. Adorno y Max Horkheimer publicada inicialmente bajo el título de Fragmentos filosóficos (1944), y conocida posteriormente como Dialéctica de la Ilustración (1947), Horkheimer y Adorno elaboran una crítica a la razón, entendida esta como la instancia de dominación tanto del hombre sobre el hombre, como de este sobre la naturaleza, denuncian la sinrazón moderna en las relaciones humanas y el ejercicio de la barbarie política y cultural del sistema mundo capitalista, evalúan las promesas de la llustración que ofrecía tanto la legitimación del saber científico, como la liberación del hombre de su sometimiento a

\section{La modernidad dio origen a la}

idea y a la representación de un

hombre-persona-sujeto actuante, dominante, que creía poder

tener el control total de su hacer

$y$ de sus deseos, el poder de la

razón asociado a la autonomía

subjetiva del espíritu humano

potenció el deseo humano de

organizar y controlar el medio

natural para manipular a los

demás y a su entorno. 
... es el reino de la razón instrumental que condujo a la pérdida de capacidad de sentido crítico y la libertad del sujeto, su evaluación conduce también a reconocer que el capitalismo triunfante ha generado antagonismos sociales por medio de la libre competencia del mercado, desembocando en una sociedad con fuertes acentos deshumanizantes por medio de la manipulación y el engaño. la naturaleza y a las tradiciones culturales irracionales. Estas promesas tenían una fe ciega en el progreso y en el optimismo de la razón, la razón se considera una herramienta al servicio de la voluntad de dominio, se propusieron entender "por qué la humanidad, en vez de entrar a un estado verdaderamente humano, se hunde en una nueva forma de barbarie" "Horkheimer y Adorno, 2006, p. 11.

Se hace igualmente una crítica demoledora a la suplantación de la "razón dialéctica" por "la razón instrumental", la cual es asumida como la forma de un pensamiento calculador que organiza el mundo, la razón instrumental es insensible frente a los fines; solo se asume como un instrumento de dominación. De hecho, en la modernidad reina la razón instrumental tanto en el dominio de la sociedad industrial como en el dominio del saber, "la ciencia misma no tiene ninguna conciencia de sí; es un instrumento. Pero la llustración es la filosofía que identifica verdad con sistema científico" (Horkheimer y Adorno, 2006, p. 1321; esta caracterización de la ciencia para los frankfurtianos es un sistema unificador que desconoce dentro de sus intereses todo tipo de preocupaciones éticas y reflexiones críticas que profundicen la comprensión de los procesos sociales; en suma, es el reino de la razón instrumental que condujo a la pérdida de capacidad de sentido crítico y la libertad del sujeto, su evaluación conduce también a reconocer que el capitalismo triunfante ha generado antagonismos sociales por medio de la libre competencia del mercado, desembocando en una sociedad con fuertes acentos deshumanizantes por medio de la manipulación y el engaño. Horkheimer y Adorno centran su atención en cómo los humanos, al tratar de dominar la naturaleza externa según sus intereses deben también aprender a dominar sus deseos internos, invocan la figura de Odiseo atado a un mástil para poder oír el canto de las sirenas sin destruirse a sí mismo, a fin de argumentar que este autodominio es la base de nuestro sentido de "identidad" mediante la socialización del individuo en la familia; a 
pesar de su tono antimoderno o antiilustrado de su crítica, Adorno y Horkheimer no rechazan el racionalismo, defienden el concepto positivo de la llustración el cual no renuncian a la utopía de la emancipación y la legitimación del saber y de la acción, su crítica se centra básicamente en la dicotomía razón-dominación, es decir, en la razón instrumental.

El pensamiento de Jürgen Habermas se inscribe en el proyecto frankfurtiano (reflexión crítica que buscaba la emancipación auténtica de la humanidad), retoma la perspectiva teorética planteada por sus colegas, describe por su parte el vasto panorama de la modernidad;

El proyecto de la Modernidad, formulado en el siglo XVIII por los filósofos de la Ilustración, consiste en desarrollar las ciencias objetivadoras, los fundamentos universalistas de la moral y el derecho y el arte autónomo [...] ilustrados de la categoría de un Condorcet tenían aun la exagerada esperanza de que las artes y las ciencias no solo conseguirán controlar las fuerzas de la naturaleza, sino también fomentar la interpretación del mundo y del propio yo, del progreso moral, la justicia de las instituciones sociales y hasta la felicidad de los seres humanos [...] el siglo XX no ha dejado mucho de este optimismo. (Habermas, 1988 p. 273).

Con ello Jürgen Habermas hace un esfuerzo plausible para reconstruir las esferas de valor y legitimidad que puedan salvar la razón ilustrada de su naufragio. Propone liberar la teoría crítica frankfurtiana de sus aporías e insuficiencias y al respecto indica que

La crítica de la razón instrumental se entiende a sí misma como una crítica de la cosificación [...]. En esta tentativa, Horkheimer y Adorno se ven envueltos en aporías, que pueden sernos muy instructivas y de las que podemos obtener razones a favor de un cambio de paradigma en teoría de la sociedad. (Habermas, 2003, vol. 1 p. 465).
La crítica de Horkheimer y Adorno a la razón ilustrada, como indica Habermas, es que ella se asume como una crítica totalitaria a la totalidad de la razón, por tanto, la razón es reducida a una mera razón instrumental cayendo en una auténtica aporía la cual, en términos habermasianos se explicita así:

En su dialéctica de la Ilustración Horkheimer y Adorno solo pretendieron ya desarrollar esta aporía, pero no intentaron buscar un camino que los sacara de ella. Ciertamente que hacen frente a la razón instrumental con cierta "anamnesis", memoria que sigue el rastro a los movimientos de una naturaleza que se resuelve, que se irrita y protesta contra su instrumentalización. Tienen también para esta resistencia un nombre, mimesis [..]. Pero esta facultad mimética escapa a una conceptuación cortada únicamente al talle de las relaciones sujeto-objeto; y así, la mimesis aparece como un impulso, como lo simplemente opuesto a la razón. (Habermas, 1989. p. 89).

Habermas reitera la crítica a Horkheimer y Adorno en el hecho de que no pudieron establecer claramente la diferencia entre saberes sometiéndolos indistintamente y globalmente a los imperativos de la razón instrumental; reitera que la crítica a la razón instrumental queda solamente determinada por la filosofía idealista del sujeto, en donde las relaciones sujeto-objeto son relaciones de dominación provenientes de un sujeto conocedor y actuante que desea disponer de la naturaleza teniendo en cuenta solamente su beneficio trayendo como consecuencias un reino de desnaturalización del hombre y deshumanización de la naturaleza, el cambio de paradigma en términos habermasianos es pasar de la filosofía del sujeto a la teoría de la acción comunicativa, en donde propone pasar de la razón cognitiva e instrumental hacia la mutua comprensión del mundo de la vida por medio de la acción comunicativa. 
Para intentar comprender la teoría de la sociedad contemporánea de Jürgen Habermas no solo basta con recurrir a la obra de Horkheimer y Adorno, sino que también sus hipótesis están estimuladas por la obra de Max Weber. Una breve caracterización de los argumentos de Weber en los que Habermas centra su atención son: Max Weber afirma que la sociedad moderna se caracteriza por el predominio de la acción racional y para ello elabora varios sentidos de lo racional; una de esas concepciones de racionalidad opuesta a la ilustrada es la caracterizada en la relación dicotómica entre "racionalidad de fines" $y$ "racionalidad con arreglo a valores"; la racionalidad de fines establece una delimitación entre los recursos de una acción con los fines establecidos o esperados; en la racionalidad con arreglo a valores, la acción se mide bajo los parámetros establecidos por creencias en valores o convicciones culturales o subjetivas (Weber, 1964, p. 20). La "racionalidad formal", una variante conceptual de la "racionalidad de fines" en términos weberianos, es asumida como un pensamiento sistemático que emplea conceptos precisos, análisis de diversos medios con relación a su eficacia para obtener un fin, asumida como el cálculo técnico a la producción de bienes, la cual es aplicada a la producción de trabajo social; esta racionalidad es el modo de conducta asumida como modelo a seguir por los ciudadanos de las sociedades capitalistas desarrolladas sometida a los imperativos del mercado (Weber, 2003, pp. 31-80). Weber pone en evidencia la "racionalidad de fines", la cual se torna dominante, y señala que el ejercicio de esta racionalidad desemboca en situaciones inhumanas, pues considera a los seres humanos como unidades discontinuas sometidas a la ley de intercambio de mercancías masificadas, el sujeto humano es cosificado en el dominio de la producción racional, situación que Weber denomina "jaula de hierro de la razón"; este tipo de racionalidad legitima el control político tecno-burocrático de las sociedades capitalistas.
En La ética protestante y el espíritu del capitalismo Max Weber ofrece numerosos ejemplos de las prácticas sociales y culturales de esta concepción de racionalidad (menciona el desarrollo de las matemáticas y la medicina basadas en la experimentación metódica, en el ámbito cultural, indica las nuevas posibilidades artísticas y arquitectónicas y el desarrollo de la música), también concibe como ejemplo de la racionalización de fines la actividad económica, la cual se racionaliza con el surgimiento de las organizaciones para la búsqueda sistemática de ganancias mediante el intercambio regularizado, estableciendo para ello una reserva de "trabajo libre"; esta forma de dominación económica y social se caracteriza por la fuerte "racionalidad administrativa" estableciendo una distinción entre propiedad económica y propiedad personal, así como la contabilidad de la eficiencia que permite el cálculo preciso de la contribución de cada uno de los factores involucrados en búsqueda de ganancias. En la recopilación de sus ensayos sobre la sociología de la religión, Weber establece la relación de la religión con cuestiones sociales y culturales y da una explicación de la ideología capitalista; para ello indica las consecuencias de la racionalidad religiosa calvinista, sostiene que los procesos religiosos fueron cruciales para la racionalización cultural y social con los cuales se creó una actitud metódica y una ética del trabajo lla conducta debe ser la de trabajar mucho, ahorrar las ganancias, y no gastar en bienes suntuarios), afín al espíritu capitalista, en la cual el trabajar por vocación protege contra el ocio y las tentaciones de los placeres mundanos, lo cual incidió en la acumulación de capital y modificó la dinámica de los intereses del desarrollo del capitalismo.

A partir de las ideas de Weber, Jürgen Habermas propone que el diagnóstico de época que Weber caracterizó tiene tanta actualidad hoy día como cuando fue presentado por primera vez (Habermas, vol. 2, p. 301). La explicación de Weber de la racionalidad cultural y social es el punto de partida de la teoría social de 
Habermas para explicar el "descarrilamiento de la locomotora marxista de la historia"; en términos habermasianos se interpreta la "jaula de hierro" como la pérdida de libertad por el surgimiento de instituciones racionales como la economía, las empresas y las burocracias capitalistas. El esfuerzo habermasiano está dirigido a establecer un diagnóstico de las consecuencias indeseables de la modernidad, argumenta que la modernización de la vida depende de una racionalización previa de la vida cultural, propone que, más que el fin de la razón, son los desarrollos culturales los que determinan el surgimiento de actitudes alternas frente al mundo de la vida, el cual se basa en el reconocimiento de diferentes dimensiones de racionalidad o diferentes "voces de razón", como la racionalidad cognitiva, racionalidad moralpráctica, racionalidad estético-expresiva. Sin embargo, la sociedad capitalista contemporánea privilegia un tipo específico de racionalidad por encima de todos los demás: se trata de un enfoque instrumental que equipara todos los fenómenos a cosas. En este punto Habermas establece la distinción entre "racionalidad instrumental" o estratégica y "racionalidad comunicativa", la primera comporta la utilización de un saber que conduce a fines, propósitos, y puede ser controlada y medida por sus logros, la segunda forma de racionalidad, la comunicativa, por el contrario, obtiene su sentido de la capacidad que posee el habla de argumentar, y con ello de unir sin coacciones, de generar consensos y de posibilitar la superación de puntos de vista gracias a una comunidad de convicciones racionales motivadas. (Habermas, 1968. p. 101 ).

Propone en consecuencia, la recuperación de la racionalidad en términos de la razón comunicativa, recurriendo a la teoría lingüística, en particular a la obra de Noam Chomsky, y a la psicología cognitiva de Jean Piaget y la teoría semiótica de Charles S. Pierce, de la cual toma la postulación metodológica de la existencia de una comunidad ideal e indefinida de comunicación y de argumentación referida a acuerdos de verdad; la "racionalidad comunicativa" habermasiana se basa en los siguientes supuestos: en primer lugar

\section{Habermas establece la distinción} entre "racionalidad instrumental" o estratégica y "racionalidad comunicativa", la primera comporta la utilización de un saber que conduce a fines, propósitos, $y$ puede ser controlada y medida por sus logros, la segunda forma de racionalidad, la comunicativa, por el contrario, obtiene su sentido de la capacidad que posee el habla de argumentar, y con ello de unir sin coacciones, de generar consensos y de posibilitar la superación de puntos de vista gracias a una comunidad de convicciones racionales motivadas... 


\section{El modelo pragmático}

habermasiano, denominado

teoría de la acción comunicativa, representa un desafío de carácter

intelectual para las ciencias de

la gestión a la hora de su puesta

en práctica frente al conflicto

histórico y dialéctico entre los

imperativos categóricos de la

racionalidad instrumental y

racionalidad sustantiva. establece una teoría de los actos de habla, la cual implica el cambio de una perspectiva meramente representacional del lenguaje a una concepción más vivencial, más expresiva y con muchos más matices de representación; en esta perspectiva, los interlocutores intervienen estableciendo lo que Habermas denomina "pretensión de validez", en la cual están abiertos a la crítica, al cuestionamiento, al rechazo, a la aceptación, haciendo de todo acto de habla un entendimiento que debe conducir a un acuerdo no forzado entre sujetos competentes lingüísticamente, su acuerdo final debe legitimar el esfuerzo comunicacional definido por Habermas como un acuerdo a partir del "asentimiento racional motivado". En segundo lugar, establece la existencia de una "situación ideal del habla", la cual supone una comunicación libre de coacción y excluyente de distorsiones propias de la comunicación lingüística, centra la postulación de una situación simétrica de oportunidades de la que deben gozar todos los participantes en un discurso determinado, y por último, establece la existencia de un "consenso racional", el cual responde a la idea en la que las cuestiones prácticas que se plantean en lo ateniente a la elección de normas, solo puede decidirse mediante un consenso instaurado entre todos los implicados y todos los afectados por el discurso. Las consecuencias de orden político de la teoría de la acción comunicativa se centran en la idea de la democratización de la sociedad como parte esencial a partir de la defensa de la opinión pública, constituyéndose en una elaboración filosófica en la que la razón es mutada en comunicación. Por otra parte, Jürgen Habermas no descree de la razón instrumental, de la razón científica y de sus potencialidades intelectivas, y cree que incrementando la comunicación racional entre estos dominios se puede alcanzar un equilibrio en su intención de liberar al hombre del sometimiento político, económico, físico, entre otros, de tal manera que la comunicación liberadora de la sociedad no se pierda por dar forma a procesos de dominación autoritaria y violenta. 


\section{El MODELO PRAGMÁTICO DE HABERMAS Y SU DESAFÍO DE CARÁCTER INTELECTUAL PARA LAS CIENCIAS DE LA GESTIÓN}

El modelo pragmático habermasiano, denominado teoría de la acción comunicativa, representa un desafío de carácter intelectual para las ciencias de la gestión a la hora de su puesta en práctica frente al conflicto histórico y dialéctico entre los imperativos categóricos de la racionalidad instrumental y racionalidad sustantiva. Habermas propone la implementación de un modelo alternativo: la "racionalidad comunicativa". Este modelo busca conciliar la antinomia entre "racionalidad instrumental" y la "racionalidad sustantiva". La "racionalidad instrumental", sinónimo de "racionalidad técnica", "racionalidad funcional", "enfatiza más los medios que la coordinación de los fines, lo que significa decir también que el valor de los fines se determina por el valor operacional de los medios. Para este tipo de razón, una idea, un concepto, o una teoría pasan de un esquema o plan de acción en el cual la probabilidad y la calculabilidad son sus nociones claves (Tenorio, 2000, p. 41). Adorno y Horkheimer como teóricos críticos denuncian que "La razón instrumental está anclada en la lógica formal, separa sin problemas hechos de valores, verdad de opiniones, argumentos objetivos de subjetivos" quedando reducida a la "razón técnica" en donde únicamente el experto (tecnócrata), por medio de la razón científica, está en capacidad de encontrar la mejor solución a problemas siempre más complejos y presentarla a los demás actores de la sociedad los cuales no tienen otra opción que el ratificarla (el one best way de Taylor)

La racionalidad instrumental tiene relación directa con el discurso del fin de las ideologías que se sustenta en la creencia de que las coacciones objetivas de la realidad no dejan otras opciones distintas a las que descubren el saber técnico o el científico. En función a los procesos de las ciencias de la gestión la racionalidad instrumental busca al interior de las organizaciones relaciones de fines y medios a través de criterios racionales para que se puedan alcanzar los objetivos previamente fijados instrumentalizando las relaciones sociales del trabajo, las personas son medios (tensa relación entre subordinador y subordinado). En el fondo las relaciones de autoridad, de poder y de subordinación, incluida la relación de trabajo, buscan negar o recortar simplemente la condición de humanidad en el otro el subordinado. La "racionalidad sustantiva" se propone alcanzar los objetivos a partir de criterios no racionales, es decir, inspirados en valores individuales desde este imperativo categórico hay un reconocimiento de los actores sociales en el interior de una organización, pero en el fondo las relaciones de autoridad, de poder y de subordinación, incluida la relación de trabajo, buscan negar o recortar simplemente la condición de humanidad en el otro subordinado.

Dicho de otra manera, la organización empresarial, por más plano que sea el diseño jerárquico, no consigue diluir en su seno, mediante un simple acto de su voluntad táctica, la fragmentación entre el "nosotros" y el "ellos" ni sus efectos sobre el conjunto. Razón por la cual el subordinado será siempre visto como una especie de "extraño" necesario, una suerte de "otro" imprescindible pero "diferente" en la organización, en la medida en que la organización reproduce en su seno, sin poderlo evitar y no obstante la retórica de la igualdad fraternal, según lo prometido por el mito del "progreso" lel cual se inicia para Occidente en Grecia y consigue llegar hasta el siglo XXI, en realidad ya demasiado maltrecho o al menos fuertemente redefinido, debido al efecto que sobre él ha tenido una severa incredulidad de sus promesas de libertad, solidaridad, fraternidad). En este sentido cabe resaltar los trabajos del profesor Alberto Guerreiro Ramos, sociólogo e intelectual brasileño, quien dedicó parte de su obra (A nova ciencia das organizacoes: uma 
reconceituacao das riqueza das naceos, Río de Janeiro, FGV, 1981) en hacer inteligibles las ciencias de la gestión desde la perspectiva de racionalidad sustantiva.

Como modelo alternativo a los imperativos categóricos de "racionalidad instrumental" y "racionalidad sustantiva" antes descritos, Habermas nos seduce intelectualmente con su teoría de la acción comunicativa, el cual para efectos de este ensayo lo conceptuamos de la misma manera como lo denomina el profesor Tenorio, "racionalidad comunicativa" (Tenorio, 2004, p. 35) para guardar coherencia epistémica. El modelo de "racionalidad instrumental" y la "racionalidad sustantiva". Habermas estima que es posible esta reconciliación por medio de la organización del diálogo interpartes y con la introducción de un tercer actor clave para la democracia, que es el trabajador, pero en su condición de ciudadano con derechos. La racionalidad comunicativa pretende conciliar el saber técnico y los valores mediante actos ilocucionarios con el fin de facilitar los procesos intersubjetivos de aprendizaje y empatía. Se busca de esta manera en el interior de las organizaciones públicas o privadas evitar actos de autoritarismo I"yo soy el jefe y por tanto, mando y decido yo") o de corte técnico ("yo soy el experto que sabe y hay que hacer esto"). Habermas propone que las decisiones sean el resultado y surian del diálogo interdisciplinal y de saberes buscando un trato más humano entre los semejantes de tal manera que, como lo supuso Karl Marx, para mencionar solo este caso, la idea de hombre que él esperaba, mediante el desarrollo de los instrumentos y técnicas, el empleo de sus propias fuerzas y de su propia razón y entendimiento, donde no existan la explotación del hombre por el hombre ni la miseria.

La "racionalidad comunicativa", si bien guarda estrecha relación con una teoría eminentemente lingüística y comunicativa, no impide el que pueda presentarse como un posible modelo interpretativo de la realidad social y organizacional en donde las prácticas sociales del mundo de la vida pública y privada no sean de exclusión sino, por el contrario, de inclusión de los sujetos que la componen por cuanto están dotados de capacidad de habla e interacción.

Jürgen Habermas, en su texto Teoría de la acción comunicativa: complementos y estudios previos, en el cual, teniendo como referente la teoría sociológica, indica que los modelos que clarifican el proceso de generación de una sociedad históricamente se podrían caracterizar así:

\section{- Teorías de fenomenología de la constitución} de la sociedad (Kant, Husserl, Berger, Luckman, Hegel, Marx, Schutz, Lukacs, Adornol suponen un sujeto trascendente, cognoscente y juzgante, el cual se constituye históricamente y constituye una realidad social (Habermas 1984, pp. 31,38$).$

- Teorías sistémicas de la evolución de la sociedad (Saussure, Levy Strauss, Parsons, Luhmann) supone estructuras sociales sin sujetos, entiende la sociedad generada por estructuras de formas simbólicas (antropología social estructuralista o estructuralismo lingüístico, el cual supone sistemas de reglas gramaticales que exigen hablantes competentes) o por flujos de información (teoría de sistemas en sociología) en donde los sujetos son autómatas que se regulan a sí mismos y no necesita a un sujeto que lo sirva (Habermas 1984, pp. 31 , 32, 33).

- Teoría de la sociedad planteada en términos de la comunicación (G. H. Mead, J. Habermas, Wittgenstein, George Simmell, supone que el proceso de generación de una sociedad está determinado por sujetos con capacidad de habla e interacción en los cuales los actos del habla tienen fines cognitivos (los sujetos hablan con razón con argumentos buscando el bien común de la sociedad y no solo por intereses de grupol como fines o reglas de acción lacciones 
comunicativas - normas sociales - y acciones instrumentales - reglas y técnicas), las cuales son medidas por relaciones intersubjetivas, es decir, los sujetos tienen juegos de roles o interaccionismos simbólicos (George Herbert Meadl y teoría de juegos de lenguaje (Wittgenstein). Bajo este orden de ideas, Habermas nos ofrece una introducción al concepto de acción comunicativa en los siguientes términos:

... el concepto de acción comunicativa presupone el lenguaje como un medio dentro del cual tiene lugar un tipo de procesos de entendimiento en cuyo transcurso los participantes, al relacionarse con un mundo se presentan unos frente a otros con pretensiones de validez que pueden ser reconocidas o puestas en cuestión. (Habermas, 1987, V. 1. p, 143)

De igual modo nos aclara que "La teoría de la acción comunicativa no es una mera teoría, sino el principio de una teoría de la sociedad que se esfuerza por dar razón de los cánones críticos de que hace uso" (Habermas, 1987, V. 1, p, 9). Más adelante afirma que "El propósito de este bosquejo argumentativo es mostrar que necesitamos de una teoría de la acción comunicativa si queremos abordar hoy de forma adecuada la problemática de la racionalidad social instrumental (las cursivas son mías). (Habermas, 1987, V. 1, p. 23).

La teoría de acción comunicativa tiene una mirada "socio-céntrica" que encuentra en el diálogo un instrumento de acción social o de responsabilidad social y que se dirige, principalmente, a buscar un acuerdo para la coordinación y ejecución de sus planes de acción en procesos de entendimiento entre los participantes en las esferas de la vida privada y de la vida pública y de opinión sobre la base de poder coordinar y ejecutar planes de acció; en este orden de ideas la teoría de la acción comunicativa (racionalidad comunicativa) es plausible en su formulación pero podríamos
Habermas propone que las

decisiones sean el resultado y surjan del diálogo interdisciplinal y de saberes buscando un trato más humano entre los semejantes de tal manera que, como lo supuso Karl Marx, para mencionar solo este caso, la idea de hombre que él esperaba, mediante el desarrollo de los instrumentos y técnicas, el empleo de sus propias fuerzas y de su propia razón y entendimiento, donde no existan la explotación del hombre por el hombre ni la miseria. 


\section{$E l$ concepto de racionalidad}

para Habermas debe entenderse

como la forma en que las personas

que usan el lenguaje son capaces de

actuar mediante el conocimiento; de

ahí que sea importante preguntarse

por el tipo de racionalidad que

deben estudiar las ciencias de la

gestión, la cual bajo la racionalidad

instrumental se preocupa por una

racionalidad de los fines... deducir también que, además de presentarse como una teoría de la sociedad, es, por decirlo de alguna forma una teoría de política de la democracia, entendida la democracia como una "democracia de poder discursivo" (Ralf Daiemdorf, 2003, p. 9), por cuanto en la vida social los hombres se intercomunican y se interrelacionan formando tejido social, - la que también podríamos denominar ejercicios de ciudadanía, a través de actos ilocucionarios. Habermas en su filosofía de la pragmática del lenguaje nos indica que el acto de hablar tiene tres modos: locucionario-acto de habla común-, perlocutivo -acto de habla estratégico, intencionado, calculado-, ilucutivo -acto de habla democrático-. Habermas sostiene además que los actos ilocucionarios no solamente representan el hecho de hablar por hablar, sino que, por el contrario, hay que estar asistido por la lógica del mejor argumento, es decir, la "razón", en donde la sustancia epistemológica de la misma vincula los términos "solidaridad", "libertad" y "justicia social", y se debe hacer conciencia de que en el acto del habla debe estar presente el bien común, el bienestar de la sociedad.

\section{CATEGORÍAS DE ANÁLISIS DESDE LA PERSPECTIVA DE RACIONALIDAD COMUNICATIVA INDISPENSABLE PARA REPENSAR LAS CIENCIAS DE LA GESTIÓN}

Para entender y superar la "racionalidad instrumental", la teoría de la "racionalidad comunicativa" establece tres categorías epistémicas de análisis indispensables para las ciencias de la gestión, tanto para sus desarrollos teóricos como para sus desarrollos prácticos: el concepto de racionalidad; el concepto del mundo de la vida; el concepto de comunicación. 


\subsection{CATEGORÍAS DE ANÁLISIS TEÓRICO DE LA "RACIONALIDAD COMUNICATIVA" PARA SER TENIDAS EN CUENTA EN EL ÁMBITO DE LA TEORÍA DE LAS CIENCIAS DE LA GESTIÓN}

El concepto de racionalidad para Habermas debe entenderse como la forma en que las personas que usan el lenguaje son capaces de actuar mediante el conocimiento; de ahí que sea importante preguntarse por el tipo de racionalidad que deben estudiar las ciencias de la gestión, la cual bajo la racionalidad instrumental se preocupa por una racionalidad de los fines, y para Habermas la sociedad democrática debe basarse en la razón y su interés es la emancipación de las personas respecto de cualquier forma de coacción; en este orden de ideas concuerdan pensadores como Karl Polanyi, quien su obra La gran transformación manifiesta que "permitir que los mecanismos del mercado dirijan solos el destino de los seres humanos y el de su medio natural, así como también el monto y la utilización del poder adquisitivo, tendría como resultado la destrucción de la sociedad". René Passet nos recuerda que "El doble reduccionismo que gobierna hoy por hoy los asuntos del planeta, lo constituye la reducción de lo político y lo social a lo económico, y todo lo económico a lo financiero. Entre la lógica de lo viviente y la del dinero se juega el porvenir del mundo". Jean Francois Chanlat, por su parte, en su reflexión sobre las ciencias sociales y la administración nos indica además que la sociedad contemporánea desde una perspectiva sociológica presenta tres tendencias: en primer lugar, "hay un culto a la empresa", en segundo lugar "existe una hegemonía de lo económico" y, por último, hay una gran "influencia creciente del pensamiento gerencial sobre las mentalidades". Max Horkheimer en el libro Crítica de la razón instrumental nos advierte que el proceso de racionalización moderna se revela cada día de nuevo como un imparable proceso de instrumentalización; señala en el prólogo de esta obra que "los avances en el ámbito de los medios técnicos se ven acompañados de un proceso de deshumanización. El progreso amenaza con destruir el objetivo que está llamado a realizar: la idea de hombre". Los anteriores argumentos evidencian las consecuencias, como diría Habermas, que podrían tener las acciones instrumentales sobre las acciones sociales (comunicativas) que impactan la dinámica y el proyecto civilizatorio que estamos construyendo con la afirmación de la razón y del progreso sustentado en sucesivas revoluciones tecnoeconómicas. Para Habermas el proyecto de la modernidad y la llustración es todavía inconcluso; en forma optimista nos invita a que las promesas de "solidaridad", "libertad" y "justicia social", para que se puedan cumplir, comencemos por fundar sobre bases nuevas nuestra comprensión de la razón, del ser humano y de la sociedad; para ello es necesario que terminemos con el paradigma de la conciencia, y que hagamos depender la racionalidad ya no directamente del sujeto, sino de la intersubjetividad, y encaminemos de este modo el pensamiento hacia una lógica de descentramiento del ego (Habermas, 2003. p, 10).

El concepto del mundo de la vida. Con el ánimo de hacer una aproximación al significado del mundo de la vida, es Husserl lel más importante representante de la fenomenología de la vida) quien da inicio a su reflexión; este concepto podríamos equipararlo a mundo cotidiano; mundo circundante; el mundo de la vida, significa para Husserl: "este mundo es el constante suelo de validez, es una fuente siempre lista de autoevidencias, una fuente a la que recurrimos sin más ni más, bien en tanto que hombres prácticos, bien en tanto que científicos" (Husserl, 1999, p. 128), constituyéndose en una "fuente inagotable de posibilidades". Este concepto es tomado por Habermas y lo explicita así "El mundo de la vida es, por así decirlo, el lugar de encuentros ilocucionarios en que pueden plantearse recíprocamente la pretensión de que sus emisiones concuerden con el mundo... y en que pueden criticar y exhibir los fundamentos de esas pretensiones 
de validez, resolver sus disentimientos y llegar a un acuerdo" (la cursiva es mía) (Habermas, 1987, v. 2, p. 179); el mundo de la vida es también para Habermas una concepción similar a la de Parsons y a la de Luhmann, es decir, está constituido por la cultura (mundo objetivo), la sociedad (mundo social) y la personalidad (mundo subjetivo); en consecuencia,

... llamo cultura al acervo de saber, en que los participantes en la comunicación se abastecen de interpretaciones para entenderse sobre algo en el mundo. Llamo sociedad a las ordenaciones legítimas a través de las cuales los participantes en la interacción regulan sus pertenencias a grupos sociales, asegurando con ello la solidaridad. Y por personalidad entiendo las competencias que convierten a un sujeto en capaz de lenguaje y de acción, esto es, que lo capacitan para tomar parte en los procesos de entendimiento y para afirmar su propia identidad. (Habermas, 1987, v. 2. p. 1961

En este sentido, advierte y plantea los siguientes desafíos a las ciencias de la gestión, que con su racionalidad instrumental lo que se busca es un proceso de "colonización del mundo de la vida", "burocratización"; "pérdida de sentido"; "pérdida de libertad", utilizando para ello entornos y medios como el subsistema económico a través de "dinero" y con el subsistema estatal el "poder"; estos hechos podríamos caracterizarlos de la siguiente forma en el ámbito de la cultura (hoy por hoy los actos crueles e inhumanos saturan la industria cultural "massmediática" cine, televisión, videojuegos, música, se deleita con la violencia: el alquiler de vientres, venta de paisaje, entre otros, en donde está en riesgo la vida misma); en el ámbito de la sociedad linstituciones como la familia, el Estado, entre otros, cada vez se alejan del mundo de la vida con menores niveles de libertad, de solidaridad y justicia social, quedando subsumidas a las lógicas del mercado); en el ámbito de la personalidad Isupone personas cada vez más enajenadas, subsumidas en sociedades enajenantes sin mayores niveles de autorrealización personal, excluidas en todos los órdenes).

Frente a este estado de cosas o desafíos Habermas presupone establecer los siguientes retos a las ciencias sociales, incluidas, por supuesto, las ciencias de la gestión: para el desafío de la "colonización del mundo de la vida" es necesario reconstituir los mecanismos de intersubjetividad en la cual haya un descentramiento del ego; para la "burocratización" es necesario que se reactiven los consensos por medio del diálogo intersubjetivo; para la "pérdida de sentido" se hace necesario reconstruir una moral formando actores sociales capaces de responder por sus acciones a través de una ética del discurso; para la "pérdida de libertad" se hace necesario repensar una nueva teoría de la racionalidad en la cual se liberen los imperativos sistémicos que agotan la capacidad del mundo de la vida que se cosifican a través de la racionalidad instrumental; en virtud de ello se hace necesario darle la posición central a un concepto clave de la filosofía crítica, como es el de la "reificación"; al respecto Axel Honneth, uno de los representantes más destacados de la actual escuela de Frankfurt, en en libro Reificación, un estudio de la teoría del reconocimiento (Kazt Editores, 2007), en un intento de restituir a la filosofía su dimensión de crítica social, sostiene que el ser humano no es una cosa o mercancía, y por el contrario, en esa lucha por la reificación o reconocimiento "El hombre solamente es hombre entre los hombres" (Fiche), es decir, la relación práctica consigo mismo se constituye en una relación con el otro (Honneth, 2007, p. 13).

El concepto comunicación. Para Habermas la comunicación por medio de la argumentación es lo que determina lo que es válido o verdadero. Es decir, el concepto de verdad no es una copia de las realidades intersubjetivas a las cuales se refieren los argumentos de los participantes en el discurso, esta debe ser el resultado consensual 
sobre la cual no actúa ninguna influencia que la distorsione; ese consenso se logra cuando se dan cuatro condiciones de validez aceptadas por todos los participantes:

1) Que el enunciado que hace un hablante sea comprensible;

2) Coordinación de la acción: que el hablante sea fiable;

3) Que la acción pretendida sea correcta por referencia a un contexto normativo vigente;

4) Que la intención del hablante sea, en efecto, la que él expresa.

Con las características señaladas, Habermas sostiene que es la acción comunicativa la que caracteriza a las interacciones que se dan en una sociedad y no la acción racional instrumental, como lo indicó Karl Marx con el "trabajo", de cuyo concepto deriva las contradicciones dialécticas entre las relaciones sociales de producción y los medios de producción. Para Habermas, en cambio, en el análisis de las relaciones sociales dialécticas de contradicción es más importante la acción comunicativa 0 el habla (desde el punto de vista simbólico el lenguaje es históricamente anterior al concepto de trabajo), es el instrumento de socialización y no el trabajo lo que le permite una comprensión, distanciamiento o aproximación de los actores sociales en contradicción; desde esta perspectiva, el "trabajador" debe ser mirado como un "ciudadano" con plenos derechos. En este contexto de ideas el reto que plantea Habermas a las ciencias de la gestión es intentar dar respuesta a los siguientes interrogantes: ¿cómo lograr que se tenga en cuenta en el interior de una organización la igualdad en el ámbito de la comunicación, por cuanto supone en su teoría de acción comunicativa sujetos con igualdad argumentativa y comunicativa?, dado que para Habermas la llustración es un proyecto inconcluso, ¿cómo conciliar la racionalidad del discurso frente a la racionalidad humana?, ¿qué herramientas utilizar en las organizaciones que permitan ejercer un control en las mismas, por cuanto cada vez más se alejan de los

\section{Para Habermas la comunicación}

por medio de la argumentación es

lo que determina lo que es válido

o verdadero. Es decir, el concepto

de verdad no es una copia de las

realidades intersubjetivas a las

cuales se refieren los argumentos de

los participantes en el discurso, esta

debe ser el resultado consensual

sobre la cual no actúa ninguna

influencia que la distorsione... 
En los procesos de producción de bienes y servicios se utilizan medios físicos, pero, sobre todo, medios humanos. Esto es así porque la robótica o toyotismo no ha terminado de apoderarse de las organizaciones. Tenemos máquinas, tecnologías de todo orden y materias primas, de un aparte; y de la otra, seres humanos que actúan como verdaderos medios en los procesos de producción, así no quiera llamárselos de ese modo ni admitir que lo son de manera efectiva. Los esclavos y los siervos del pasado fueron medios humanos sin derechos. ciudadanos? Además de lo anterior, asistimos a un mundo en donde los fenómenos de la globalización e internacionalización quitan espacios en las organizaciones a las posibilidades genuinamente democráticas; frente a este estado de cosas se hace necesario repensar las organizaciones para que trabajen sobre una nueva "democracia con poder discursivo" que brinde respuestas coherentes a las siguientes preguntas, como sostiene Ralf Dahienrdorf (2003, pp. 9, 10): ¿̇cómo podemos producir en nuestras sociedades cambios sin violencia?, ¿cómo podemos, mediante un sistema controlar a quienes están en el poder de modo que tengamos certeza de que no abusan de él? ¿̇cómo pueden los ciudadanos tener voz en el ejercicio del poder?

\subsection{CATEGORÍAS DE ANÁLISIS DE LA "RACIONALIDAD COMUNICATIVA" PARA TENER EN CUENTA EN EL ÁMBITO DE LA TEORÍA DE LAS CIENCIAS DE LA GESTIÓN}

No existe una disciplina académica más proclive a las modas y más afectada por la velocidad del mundo contemporáneo que las ciencias de la gestión como cuerpo de fórmula para el éxito y la "buena" marcha de las organizaciones, en términos de la productividad y competitividad que demanda un planeta globalizado. Sin embargo, la misión académica debe cumplirse por fuera de las "modas", su tiempo es otro y sus resultados se miden por el desarrollo del conocimiento mediante la crítica rigurosa y responsable, ojalá unida al diseño de soluciones a problemas humanos y sociales, a través de la ciencia aplicada a la técnica y la tecnología. No obstante, el uso de la técnica y la tecnología plantea no pocas veces fuertes dificultades de tipo ético y filosófico. No faltan quienes piensan que la ética es solo para recitarla (ver al respecto Ética del discurso y la cuestión de la verdad, de Habermas) en los salones, aunque para eludirla en la acción concreta, porque para la racionalidad 
instrumental resulta un estorbo respetarla en donde está en juego la idea misma de "ser humano". En los procesos de producción de bienes y servicios se utilizan medios físicos, pero, sobre todo, medios humanos. Esto es así porque la robótica o toyotismo no ha terminado de apoderarse de las organizaciones. Tenemos máquinas, tecnologías de todo orden y materias primas, de un aparte; y de la otra, seres humanos que actúan como verdaderos medios en los procesos de producción, así no quiera llamárselos de ese modo ni admitir que lo son de manera efectiva. Los esclavos y los siervos del pasado fueron medios humanos sin derechos. En la modernidad los operarios y los empleados siguieron siendo instrumentos mediáticos de la producción, aunque rodeados de un mínimo de derechos. Sobre estos medios humanos con derechos reconocidos por la ley y la filosofía se sostiene la lógica objetiva de la racionalidad productiva instrumental contemporánea, que por algún motivo evidente Habermas denomina "afraternal".

El "desvelamiento" científico de las lógicas humanas, sociales y reales y el modo como actúan los intereses de la producción en las organizaciones tienen al menos dos opciones para elegir; la del pensamiento crítico con fundamento ético, de una parte, y la de pensar en nuevas utopías como la de un "nuevo pensamiento administrativo" en el cual una posible salida podría constituirla la "racionalidad comunicativa" de Habermas; por cuanto la racionalidad instrumental dificulta la autonomía social de los diferentes actores sociales, en esa búsqueda podría estar lo que algunos cientistas sociales, entre ellos el profesor Fernando Guilherme Tenorio, han denominado el "tercer sector", ampliando una nueva discusión epistémica y dicotómica para las ciencias de la gestión entre el concepto de gestión fonológica lesta perspectiva teórica se caracteriza por tener: acción sociales de gerenciamiento estratégico, con lógicas de invisibilización y de exclusión de los actores sociales, fundamentando su metodología de trabajo en el cálculo utilitarista de medios como el dinero y el poder, fondistas, con acciones teleológico-estratégico y colonizadora del mundo de la vida, donde prevalece el monólogo de lo individuall y el concepto gestión dialógica o social lesta perspectiva teórica es de inclusión y en ella se humanizan las organizaciones y se les da los trabajadores empoderamiento para que tomen decisiones que den dirección a la organización, creando con ello tejido social, solidaridad y cooperación, en la cual prevalece el diálogo colectivo) en un intento por salir del fatalismo de orden y progreso (Tenorio 2004, p. 17).

\section{4. la gestión diALÓGICA O GESTIÓN SOCIAL COMO PROPUESTA DE BIFURCACIÓN PARA SALIR DE LA LÓGICA DE LA RACIONALIDAD INSTRUMENTAL}

En concordancia con la hipótesis del profesor Fernando G. Tenorio, la gestión dialógica o social es sin duda, desde la perspectiva de la "racionalidad comunicativa" de Habermas, un intento concreto y real (un ejemplo claro lo caracterizan todos los micro y macroemprendimientos del sector en la denominada "economía solidaria") de bifurcación para salir de "la racionalidad instrumental". El tema de la gestión social es hoy de gran actualidad en las ciencias sociales, pero quienes enfatizan en el diálogo y la solidaridad y en ello hace sentido la definición que nos comparte Habermas del concepto de sociedad "Llamo sociedad a las ordenaciones legítimas a través de las cuales los participantes en la interacción regulan sus pertenencias a grupos sociales, asegurando con ello la solidaridad" (Habermas, 1987, v. 2, p. 196) han tendido a considerar con distancia y a menudo sospechosamente la dedicación a los negocios y actividades solidarias. Por cuanto la 
idea de solidaridad se inserta en un llamado ético y cultural de fraternidad humana, hace referencia a vínculos de amistad, reciprocidad y ayuda mutua. Este tipo de gestión, como lo sostiene el profesor Tenorio, invierte las categorías Estado-sociedad por sociedad-Estado y capitaltrabajo por trabajo-capital, enfatizando positiva y valorativamente en que son la sociedad y el trabajo las categorías más importantes en contravía del doble reduccionismo con el que se explica la racionalidad instrumental en donde son la economía y el mercado los que explican las realidades sociales.

No sobra advertir que mirado el término gestión social como discurso, como lenguaje. Por cuanto también la teoría de la acción comunicativa de Habermas guarda estrecha relación con una teoría eminentemente lingüística, se genera lo que en lingüística se denomina oxímoron lesto es, superponer dos términos contradictorios, "una guerra limpia"). Estas manipulaciones de la lengua tienen evidentemente como objetivo el camuflaje, anulando la negatividad asociada a uno de los términos, para remplazarla por la valoración positiva que se le da al otro término. Al darle el calificativo de "limpia", la guerra se torna aceptable con ello que se quiere resaltar que las palabras "gestión" y "social", siendo habituales en el lenguaje común como es el pensamiento ilustrado, forman parte de "discursos" separados la palabra gestión se inserta en un lenguaje fáctico, instrumental y en un discurso científico: lo "social"; en un lenguaje valórico y un discurso ético este tipo de contradicciones se hace necesario superarlas. Poner unidas en una misma expresión la gestión y lo social es un proceso intelectual complejo en el que debe desenvolverse paralela y convergente en dos direcciones: por un lado, se trata de desarrollar un discurso ético y axiológico, por el que se recupere la gestión como un espacio de realización y actuación de valores y fuerzas de solidaridad; por el otro, de desarrollar un proceso interno a las ciencias de la gestión de reconocimiento y actuación a la idea de ilocución unida con el valor de la justicia social y la solidaridad cuando decimos, gestión social debemos plantear la necesidad de introducir lo social en la gestión, lo social en la teoría y en la práctica de tal forma que opere en las diferentes fases del ciclo de gestión, o sea, en la producción, circulación, consumo y acumulación. Ello implica producir con solidaridad, distribuir con solidaridad, consumir con solidaridad, acumular y desarrollar con solidaridad, posibilitando un nuevo modo de hacer gestión y economía, y una nueva racionalidad económica sustentada no en la racionalidad instrumental, sino, por el contrario, en la racionalidad comunicativa. La gestión social no es una negación de la economía del mercado; ella debe expresar una orientación fuertemente crítica y decididamente transformadora respecto de las grandes estructuras y los modos de organización y de acción que caracterizan la economía contemporánea, replanteando cuestiones éticas y morales como ¿̀para qué producir?, ¿quién se enriquece?, ¿cómo?, ¿hasta qué límite?, ¿̇en detrimento de quién y de qué?

\section{REFLEXIONES FINALES}

- La Escuela de Frankfurt se constituye en una corriente filosófica, sociológica y política, además es una alternativa epistémica crítica para las ciencias sociales, permitiéndoles a los cientistas sociales hacer inteligibles las problemáticas de la sociedad moderna; desde la perspectiva de las ciencias de la gestión ayuda con su enfoque crítico e interdisciplinario a interpretar la realidad de las organizaciones en la sociedad burguesa para ayudar a la emancipación del hombre y la sociedad.

- Una de las referencias más explícitas de la teoría crítica para interpretar la modernidad como proyecto inconcluso la plantea el filósofo alemán Jürgen Habermas (frankfurtiano de la segunda generación). Tiene un pensamiento más optimista y propone la implementación de un modelo alternativo: la "racionalidad 
comunicativa". Este modelo busca conciliar la antinomia entre "racionalidad instrumental" versus la "racionalidad sustantiva", el cual representa una salida al "pesimismo crítico" referenciado en su sentido frankfurtiano de la primera generación.

- El modelo pragmático habermasiano, denominado teoría de la acción comunicativa, representa un desafío de carácter intelectual para las ciencias de la gestión a la hora de su puesta en práctica frente al conflicto histórico y dialéctico entre los imperativos categóricos de la racionalidad instrumental y racionalidad sustantiva.

- El modelo de "racionalidad comunicativa" busca una conciliación entre las posiciones legítimas entre la "racionalidad instrumental" y la "racionalidad sustantiva". Habermas estima que es posible esta reconciliación por medio de la organización del diálogo interpartes y con la introducción de un tercer actor clave para la democracia, que es el trabajador, pero en su condición de ciudadano con derechos. La racionalidad comunicativa pretende conciliar el saber técnico y los valores mediante actos ilocucionarios con el fin de facilitar los procesos intersubjetivos de aprendizaje y empatía. Se busca de esta manera en el interior de las organizaciones públicas o privadas evitar actos de autoritarismo ("yo soy el jefe $y$, por tanto, mando y decido yo") o de corte técnico ("yo soy el experto que sabe y hay que hacer esto"). Habermas propone que las decisiones sean el resultado y surjan del diálogo interdisciplinal.

- El concepto de racionalidad para Habermas debe entenderse como la forma en que las personas que usan el lenguaje son capaces de actuar mediante el conocimiento, de ahí que sea importante preguntarse por el tipo de racionalidad que deben estudiar las ciencias de la gestión, la cual bajo la racionalidad instrumental está preocupada

\section{El concepto de racionalidad para} Habermas debe entenderse como la forma en que las personas que usan el lenguaje son capaces de actuar mediante el conocimiento, de ahí que sea importante preguntarse por el tipo de racionalidad que deben estudiar las ciencias de la gestión, la cual bajo la racionalidad instrumental está preocupada por una racionalidad de los fines y para Habermas la sociedad democrática debe basarse en la razón y su interés en la emancipación de las personas respecto de cualquier forma de coacción. 
... la gestión dialógica o social es, sin duda, desde la perspectiva de

$$
\text { la "racionalidad comunicativa" }
$$

de Habermas, un intento concreto

y real lo constituye el tercer sector

(un ejemplo claro lo caracterizan

todos los micro y macro-

emprendimientos del sector en la

denominada "economía solidaria")

de bifurcación para salir de la

"racionalidad instrumental". por una racionalidad de los fines y para Habermas la sociedad democrática debe basarse en la razón y su interés en la emancipación de las personas respecto de cualquier forma de coacción.

- Habermas presupone establecer los siguientes retos a las ciencias sociales, incluidas, por supuesto, las ciencias de la gestión: para el desafío de la "colonización del mundo de la vida" es necesario reconstituir los mecanismos de intersubjetividad en la cual haya un descentramiento del ego; para la "burocratización" es necesario que se reactiven los consensos por medio del diálogo intersubjetivo; para la "pérdida de sentido" se hace necesario reconstruir una moral formando actores sociales capaces de responder por sus acciones a través de una ética del discurso; para la "pérdida de libertad" se hace necesario repensar una nueva teoría de la racionalidad en la cual se liberen los imperativos sistémicos que agotan la capacidad del mundo de la vida que se cosifican a través de la racionalidad instrumental; en virtud de ello se hace necesario darle la posición central a un concepto clave de la filosofía crítica, la "reificación".

- Habermas sostiene que es la acción comunicativa la que caracteriza a las interacciones que se dan en una sociedad y no la acción racional instrumental, como lo indicó Karl Marx; tal acción la relaciona Marx con el "trabajo", de cuyo concepto deriva las contradicciones dialécticas entre las relaciones sociales de producción y los medios de producción. Para Habermas, en cambio, en el análisis de las relaciones sociales dialécticas de contradicción es más importante la acción comunicativa o el habla (desde el punto de vista simbólico el lenguaje es históricamente anterior al concepto de trabajo), es el instrumento de socialización y no el trabajo lo que permite una comprensión, distanciamiento o aproximación de los 
actores sociales en contradicción; desde esta perspectiva el "trabajador" debe ser mirado como un "ciudadano" con plenos derechos.

- Para las ciencias de la gestión, Habermas plantea dar respuesta a los siguientes interrogantes: ¿̇cómo lograr que se tenga en cuenta en el interior de una organización igualdad en el ámbito de la comunicación por cuanto supone en su teoría de acción comunicativa sujetos con igualdad argumentativa y comunicativa?, dado que para Habermas la llustración es un proyecto inconcluso, ¿̇cómo conciliar la racionalidad del discurso frente a la racionalidad humana?, ¿qué herramientas utilizar en las organizaciones que permitan ejercer un control en las mismas, por cuanto cada vez se alejan más de los ciudadanos?

- En concordancia con la hipótesis del profesor Fernando G. Tenorio, la gestión dialógica o social es, sin duda, desde la perspectiva de la "racionalidad comunicativa" de Habermas, un intento concreto y real lo constituye el tercer sector (un ejemplo claro lo caracterizan todos los micro y macro-emprendimientos del sector en la denominada "economía solidaria") de bifurcación para salir de la "racionalidad instrumental".

- Poner unidas en una misma expresión la gestión y lo social es un proceso intelectual complejo en el que debe desenvolverse paralela y convergentemente en dos direcciones: por un lado, se trata de desarrollar un discurso ético y axiológico, por el que se recupere la gestión como un espacio de realización y actuación de valores y fuerzas de solidaridad; por el otro, de desarrollar un proceso interno a las ciencias de la gestión de reconocimiento y actuación a la idea de ilocución unida con el valor de la justicia social y la solidaridad; cuando decimos gestión social debemos plantear la necesidad de introducir lo social en la gestión, lo social en la teoría y en la práctica de tal forma que opere en las diferentes fases del ciclo de gestión, o sea, en la producción, circulación, consumo y acumulación. Ello implica producir con solidaridad, distribuir con solidaridad, consumir con solidaridad, acumular y desarrollar con solidaridad, posibilitando un nuevo modo de hacer gestión y economía, y una nueva racionalidad económica sustentada no en la racionalidad instrumental sino, por el contrario, en la racionalidad comunicativa.

\section{REFERENCIAS}

Fernando G. Tenorio, Notas de clase, módulo "Pensamiento crítico y pensamiento administrativo", período julio-agosto, 30/07 a 10/08 de 2007.

Benjamin, Walter (1967). Ensayos escogidos. Editorial Sur, S.A.

Chanlat, Jean Francois (2002). Ciencias Sociales y Administración. Fondo Editorial Universidad EAFIT Colombia.

Guerreiro Ramos, Alberto (1981). A nova ciencia das organizacoes: uma reconceituacao das riquezas das naceos. Río de Janeiro: FGV.

Dahrendorf, Ralf (2003). Teoría de la acción comunicativa. II. Crítica de la razón funcionalista. Editorial Taurus.

Marx, Karl (1962). El capital, tomos I, II, III. México: Fondo de Cultura Económica.

Habermas, Jürgen (2003). Teoría de la acción comunicativa. I. Racionalidad de la acción y racionalidad social. Editorial Taurus.

Habermas, Jürgen (2003). Teoría de la acción comunicativa. II. Crítica de la razón funcionalista. Editorial Taurus.

Habermas, Jürgen (2004). Acción comunicativa y razón sin trascendencia. Editorial Paidos.

Habermas, Jürgen (1968). Escritos sobre moralidad y etnicidad. Editorial Paidos. 
Habermas, Jürgen (2003). La Ética del discurso y la cuestión de la verdad. Editorial Paidos.

Habermas, Jürgen (1988). La modernidad, un proyecto inacabado. Ensayos políticos. Barcelona.

Habermas, Jürgen (1989). El discurso filosófico de la modernidad. Editorial Taurus.

Hegel, Georg Wilhelm Friedrich (1974). Lecciones sobre filosofía de la historia universal. Revista de Occidente. Madrid, 43.

Honneth, Axel (2007). Reificación, un estudio en la teoría del reconocimiento. Editorial Katz.

Horkheimer, Max; Adorno, Teodor (2006). Dialéctica de la llustración. Editorial Trotta.

Horkheimer, Max (1974). Eclipse of Reason. New York: Seabury Press.
Kant, Immanuel (1964). Respuesta a la pregunta ¿Qué es la llustración? En: Filosofía de la historia. Editorial Nova.

Tenorio, Fernando G. (2004). Tem Razao a Administracao? Ensaios de teoría organizacional. Editorial Unijui. 2. ed. rev.

Tenorio, Fernando G. (2004). Um espectro ronda o terceiro setor, o espectro do mercado. Ensaios de gestao social. Editorial Unijui. 2. ed. rev.

Suárez Molano, José Olimpo (2006). Crítica a la razón en la filosofía del siglo XX. Editorial Universidad de Antioquia.

Weber, Max (1964). Economía y sociedad, esbozo de sociología comprensiva. Fondo de Cultura Económica.

Weber, Max (2003). La Ética protestante y el espíritu del capitalismo. Fondo de Cultura Económica. 